\title{
Role of heat shock protein 27 in transforming growth factor- $\beta$ - stimulated vascular endothelial growth factor release in osteoblasts
}

\author{
KENJI KATO ${ }^{1,2}$, HARUHIKO TOKUDA ${ }^{2,3}$, SEIJI ADACHI ${ }^{2}$, RIE MATSUSHIMA-NISHIWAKI ${ }^{2}$, \\ JUNICHI YAMAUCHI ${ }^{2}$, HIDEO NATSUME $^{1,2}$, CHIHO MINAMITANI $^{1}$, JUN MIZUTANI $^{1}$, \\ TAKANOBU OTSUKA $^{1}$ and OSAMU KOZAWA ${ }^{2}$
}

\author{
${ }^{1}$ Department of Orthopedic Surgery, Nagoya City University Graduate School of Medical Sciences, Nagoya 467-8601; \\ ${ }^{2}$ Department of Pharmacology, Gifu University Graduate School of Medicine, Gifu 501-1194; ${ }^{3}$ Department \\ of Clinical Laboratory, National Center for Geriatrics and Gerontology, Obu 474-8511, Japan
}

Received October 15, 2010; Accepted December 3, 2010

DOI: $10.3892 / \mathrm{ijmm} .2011 .595$

\begin{abstract}
We have previously reported that transforming growth factor- $\beta$ (TGF- $\beta$ ) stimulates heat shock protein 27 (HSP27) induction via $\mathrm{p} 44 / \mathrm{p} 42$ mitogen-activated protein (MAP) kinase, p38 MAP kinase and stress-activated protein kinase/c-Jun N-terminal kinase in osteoblast-like MC3T3-E1 cells, and that the release of vascular endothelial growth factor (VEGF) is induced by TGF- $\beta$ in these cells. In the present study, we investigated the effect of HSP27 knockdown on the TGF- $\beta$-stimulated VEGF release in these cells. Gene silencing using short interfering RNA against HSP27 (HSP27-siRNA) significantly suppressed the TGF- $\beta$-induced VEGF release. Immunofluorescence microscopy also revealed that HSP27-siRNA suppressed the TGF- $\beta$-stimulated VEGF induction as well as the reduction of HSP27 induction in these cells. However, the mRNA expression of VEGF stimulated by TGF- $\beta$ was not reduced even in cells transfected with HSP27siRNA. These results strongly suggest that HSP27 induction is critical for TGF- $\beta$-induced VEGF release in osteoblasts.
\end{abstract}

\section{Introduction}

Heat shock proteins (HSPs) are expressed when the cells are exposed to biological stress such as heat stress and chemical stress (1). HSPs are classified into high-molecular-weight HSPs and low-molecular-weight HSPs based on the apparent molecular sizes. Low-molecular-weight HSPs with molecular masses from 10-30 kDa, such as heat shock protein 27 (HSP27), $\alpha \mathrm{B}$-crystallin and HSP20, have a highly homologous amino acid sequence in their $\alpha$-crystallin domain $(2,3)$.

Correspondence to: Dr Osamu Kozawa, Department of Pharmacology, Gifu University Graduate School of Medicine, Gifu 501-1194, Japan

E-mail: okozawa@gifu-u.ac.jp

Key words: heat shock protein 27, transforming growth factor- $\beta$, vascular endothelial growth factor, osteoblast
It is well recognized that the high-molecular-weight HSPs act as chaperones that interact with other denatured proteins to facilitate normal cell functions. On the other hand, the functions of the low-molecular-weight HSPs are less known. Among the low-molecular-weight HSPs, HSP27 has been discovered as an inhibitor of actin polymerization. HSP27 becomes rapidly phosphorylated in response to various types of stress, as well as to exposure to cytokines and mitogens $(4,5)$. Under unstimulated conditions, HSP27 exists in a highmolecular weight aggregated form. It is rapidly dissociated as a result of phosphorylation (6,7). It has been shown that HSP27 is implicated in cell survival, cell differentiation and tumor progression in addition to chaperoning functions. However, the exact roles of HSP27 and the implication of its phosphorylation have not yet been clarified.

Bone metabolism is mainly regulated by two functional cells, the osteoblasts and osteoclasts, responsible for bone formation and bone resorption, respectively (8). The formation of bone structures and bone remodeling are reportedly the result of the following coupling process, bone resorption by the activated osteoclasts with subsequent deposition of new matrix by the osteoblasts. In previous studies (9-12), we have reported that various physiological regulators of the bone, such as endothelin-1, prostaglandin F2 $\alpha$ (PGF2 $\alpha$ ), PGD2 and basic fibroblast growth factor stimulate the induction of HSP27 in osteoblast-like MC3T3-E1 cells. It has been shown that down-regulation of proliferation is accompanied by a transient increase of HSP27 mRNA expression in osteoblasts (13). However, the exact role of HSP27 in osteoblasts remains unclear.

Transforming growth factor- $\beta$ (TGF- $\beta$ ) is a multifunctional cytokine that regulates cell growth, differentiation and extracellular matrix production $(14,15)$. In bone tissue, TGF- $\beta$ is produced by osteoblasts, and is abundantly stored in a latent form in bone matrix tissue (16). During the process of bone resorption by activated osteoclasts, generated active TGF- $\beta$ stimulates the recruitment and proliferation of osteoblasts responsible for new bone formation (16), indicating its essential role in the bone remodeling process. Although the intracellular signaling of TGF- $\beta$ is characterized by the Smad 
signaling pathway, it is recognized that Smad-independent signaling, such as that of the mitogen-activated protein (MAP) kinase superfamily, also plays a crucial role in the intracellular signal transduction mechanism of TGF- $\beta(14,15)$. In our previous studies in osteoblast-like MC3T3-E1 cells $(17,18)$, we have shown that TGF- $\beta$ stimulates HSP27 induction through the activation of three major MAP kinases, the p44/p42 and p38 MAP kinases, and the stress-activated protein kinase/c-Jun N-terminal kinase (SAPK/JNK).

It is well recognized that VEGF is an angiogenic growth factor displaying high specificity for vascular endothelial cells (19). As for bone metabolism, it has been shown that inactivation of VEGF causes complete suppression of blood vessel invasion concomitant with impaired trabecular bone formation and expansion of the hypertrophic chondrocyte zone in the mouse tibial epiphyseal growth plate (20). Furthermore, accumulating evidence indicates that among the bone cells, osteoblasts synthesize and secrete VEGF in response to various physiological agents $(19,21-23)$. We have previously reported that TGF- $\beta$ stimulates VEGF synthesis and release via three major MAP kinases in osteoblast-like MC3T3-E1 cells $(24,25)$, suggesting the relationship between HSP27 induction and VEGF release. Based on the assessment of their time course, the induction of HSP27 reaches its peak at $12 \mathrm{~h}$ after the stimulation of TGF- $\beta$ and decreases thereafter, while TGF- $\beta$-induced VEGF release is sustained up to $48 \mathrm{~h}$. These findings lead us to speculate that HSP27 induction plays a role in VEGF release in osteoblasts.

In the present study, we investigated how HSP27 is implicated in the TGF- $\beta$-stimulated VEGF release from osteoblast-like MC3T3-E1 cells. We herein show that HSP27 induction is indispensable for the TGF- $\beta$-induced VEGF release in these cells.

\section{Materials and methods}

Materials. TGF- $\beta$ and the mouse VEGF enzyme-linked immunosorbent assay (ELISA) kit were purchased from R\&D Systems, Inc. (Minneapolis, MN). Anti-HSP27 antibodies, anti-HSP70 antibodies, anti-HSP90 antibodies and anti-glyceraldehyde 3-phosphate dehydrogenase (GAPDH) antibodies for Western blot analysis were obtained from Santa Cruz Biotechnology, Inc. (Santa Cruz, CA). The ECL Western blotting detection system was purchased from GE Healthcare UK Ltd. (Buckinghamshire, UK). Control short interfering RNA (siRNA; Silencer Negative Control no. 1 siRNA) or HSP27siRNAs (Silencer Predesigned siRNA, 159311 and 102070, presented as \#1 and \#2, respectively) were purchased from Ambion (Austin, TX). siLentFect was purchased from Bio-Rad (Hercules, CA). TRIzol reagent was purchased from Invitrogen (Carlsbad, CA). The Omniscript Reverse Transcriptase kit was purchased from Qiagen (Hilden, Germany). Fast-start DNA Master SYBR-Green I was purchased from Roche Diagnostics (Mannheim, Germany). Other materials and chemicals were obtained from commercial sources.

Cell culture. Cloned osteoblast-like MC3T3-E1 cells derived from newborn mouse calvaria (26) were maintained as previously described (27). Briefly, the cells were cultured in $\alpha$-minimum essential medium ( $\alpha$-MEM) containing $10 \%$ fetal calf serum (FCS) at $37^{\circ} \mathrm{C}$ in a humidified atmosphere of $5 \% \mathrm{CO}_{2} / 95 \%$ air. The cells were seeded into $35-\mathrm{mm}$ $\left(5 \times 10^{4} / \mathrm{dish}\right)$ or $90-\mathrm{mm}\left(25 \times 10^{4} / \mathrm{dish}\right)$ diameter dishes in $\alpha$-MEM containing $10 \%$ FCS. After 5 days, the medium was exchanged for $\alpha$-MEM containing $0.3 \%$ FCS. The cells were used for experiments after $48 \mathrm{~h}$.

siRNA transfection. To knock down HSP27 in MC3T3-E1 cells, the cells were transfected with negative control siRNA or HSP27-siRNA utilizing siLentFect according to the manufacturer's protocol. In brief, the cells ( $1 \times 10^{5}$ cells) were seeded into $35-\mathrm{mm}$ diameter dishes in $\alpha$-MEM containing $10 \%$ FCS and sub-cultured for $48 \mathrm{~h}$. The cells were then incubated at $37^{\circ} \mathrm{C}$ with $50 \mathrm{nM}$ siRNA-siLentFect complexes. After $24 \mathrm{~h}$, the medium was exchanged to $\alpha$-MEM containing $0.3 \%$ FCS. They were then stimulated with $5 \mathrm{ng} / \mathrm{ml}$ TGF- $\beta$ in $\alpha$-MEM containing $0.3 \%$ FCS for the indicated periods.

Western blot analysis. The cells were washed twice with phosphate-buffered saline (PBS) and then lysed, homogenized and sonicated in a lysis buffer containing $62.5 \mathrm{mM}$ Tris $/ \mathrm{HCl}$ (pH 6.8), 2\% sodium dodecyl sulfate (SDS), $50 \mathrm{mM}$ dithiothreitol and $10 \%$ glycerol. The cytosolic fraction was collected as a supernatant after centrifugation at $12,500 \mathrm{x} \mathrm{g}$ for $10 \mathrm{~min}$ at $4^{\circ} \mathrm{C}$. SDS-polyacrylamide gel electrophoresis (PAGE) was performed according to Laemmli (28) in a $10 \%$ polyacrylamide gel. Western blot analysis was performed as described previously (29) by using anti-HSP27, anti-HSP70, anti-HSP90 and anti-GAPDH antibodies, and peroxidase-labeled antibodies raised in goat against rabbit IgG as secondary antibodies. The peroxidase activity on the PVDF membrane was visualized on X-ray film by means of the ECL Western blot detection system.

Assay for VEGF. The cultured cells transfected with siRNA were stimulated with $5 \mathrm{ng} / \mathrm{ml}$ of TGF- $\beta$ in $1 \mathrm{ml}$ of $\alpha$-MEM containing $0.3 \% \mathrm{FCS}$ for $48 \mathrm{~h}$. The conditioned medium was collected at the end of the incubation, and the VEGF release was measured by the VEGF ELISA kit according to the manufacturer's instructions. The assay kit can detect the mouse VEGF in the range between 7.8 and $500 \mathrm{pg} / \mathrm{ml}$. When the samples generated values $>500 \mathrm{pg} / \mathrm{ml}$, the samples were adequately diluted with a calibrator diluent provided with the kit, and then were re-assayed. The absorbance of the ELISA samples was measured at $450 \mathrm{~nm}$ with the EL340 Bio Kinetic Reader (Bio-Tek Instruments, Inc., Winooski, VT).

Real-time RT-PCR. Cultured cells transfected with siRNA were stimulated by $5 \mathrm{ng} / \mathrm{ml}$ TGF- $\beta$ for the indicated periods. Total RNA was isolated and transcribed into complementary DNA using the TRIzol reagent and the Omniscript Reverse Transcriptase kit, respectively. Real-time RT-PCR was performed using a LightCycler system (Roche Diagnostics) in capillaries and FastStart DNA Master SYBR-Green I provided with the kit. Sense and antisense primers were synthesized based on the report of Simpson et al (30) for mouse VEGF mRNA and GAPDH mRNA. The amplified products were evaluated by both a melting curve analysis and agarose electrophoresis. The VEGF mRNA levels were normalized to those of GAPDH mRNA. 
Immunofluorescence microscopystudies. Immunofluorescence microscopy studies were performed as previously described (31). In brief, the live cells grown on coverslip-bottom dishes were first treated with or without siRNA of HSP27 for $48 \mathrm{~h}$ at $37^{\circ} \mathrm{C}$, followed by stimulation with TGF- $\beta$ for $24 \mathrm{~h}$. They were then fixed with $3 \%$ paraformaldehyde and exposed to $0.1 \%$ Triton X-100 for membrane permeabilization. After washing, fixed cells were exposed to anti-VEGF antibodies and anti-HSP27 antibodies, followed by exposure to Alexa Fluor $488^{\circledR}$ conjugated goat anti-rabbit IgG and Alexa Fluor $546^{\circledR}$ conjugated goat anti-mouse IgG antibodies. Finally, they were exposed to DAPI (Wako Inc. Tokyo, Japan) for $20 \mathrm{~min}$ and the cells were then examined by fluorescence microscopy, Biorevo (BZ-9000) (Keyence, Tokyo, Japan) according to the manufacturer's protocol.

Statistical analysis. The data were analyzed by ANOVA followed by the Bonferroni method for multiple comparisons between the indicated pairs, and a $\mathrm{P}<0.05$ was considered significant. All data are presented as the mean \pm SEM of triplicate determinations. Each experiment was repeated at least three times with similar results.

\section{Results}

Effect of HSP27-siRNA on TGF- $\beta$-stimulated HSP27 induction in MC3T3-E1 cells. We first examined whether or not gene silencing using HSP27-siRNA suppresses TGF- $\beta$-stimulated HSP27 induction in osteoblast-like MC3T3-E1 cells. According to our previous report showing that the maximum effect of TGF- $\beta$ on the accumulation of HSP27 occurs $12 \mathrm{~h}$ after stimulation (17), we performed the experiments under the condition of TGF- $\beta$ stimulation for $12 \mathrm{~h}$. Both types of siRNAs successfully reduced the protein levels of HSP27 stimulated by TGF- $\beta$ (Fig. 1). On the contrary, HSP27-siRNA either with or without TGF- $\beta$ did not affect the protein levels of HSP70 or HSP90 in these cells (Fig. 1).

Effect of HSP27-knock down on TGF- $\beta$-stimulated VEGF release in MC3T3-E1 cells. We have previously reported that TGF- $\beta$ induces the expression of HSP27 and subsequently stimulates VEGF release in osteoblast-like MC3T3-E1 cells $(17,24)$. To clarify whether HSP27 induction is involved in TGF- $\beta$-induced release of VEGF, we next investigated the effects of the HSP27 down-regulation on VEGF release stimulated by TGF- $\beta$ in MC3T3-E1 cells. In a previous study (24), we have demonstrated that the maximum effect of TGF- $\beta$ on the VEGF release occurs at $48 \mathrm{~h}$. Thus, we examined the VEGF release stimulated by TGF- $\beta$ for $48 \mathrm{~h}$ in HSP27-knock down MC3T3-E1 cells. In comparison with the control cells, the TGF- $\beta$-stimulated VEGF release was significantly diminished in HSP27-knock down cells (Fig. 2). Treatment with HSP27-siRNA \#1 suppressed the TGF- $\beta$ stimulated VEGF release by approximately $70 \%$ (Fig. 2). The treatment with HSP27-siRNA \#2 also significantly suppressed the TGF- $\beta$-stimulated VEGF release (data not shown).

Effect of HSP27-knock down on TGF- $\beta$-stimulated VEGF mRNA expression in MC3T3-El cells. To clarify whether or not the suppression by HSP27 knock down of TGF- $\beta$ -

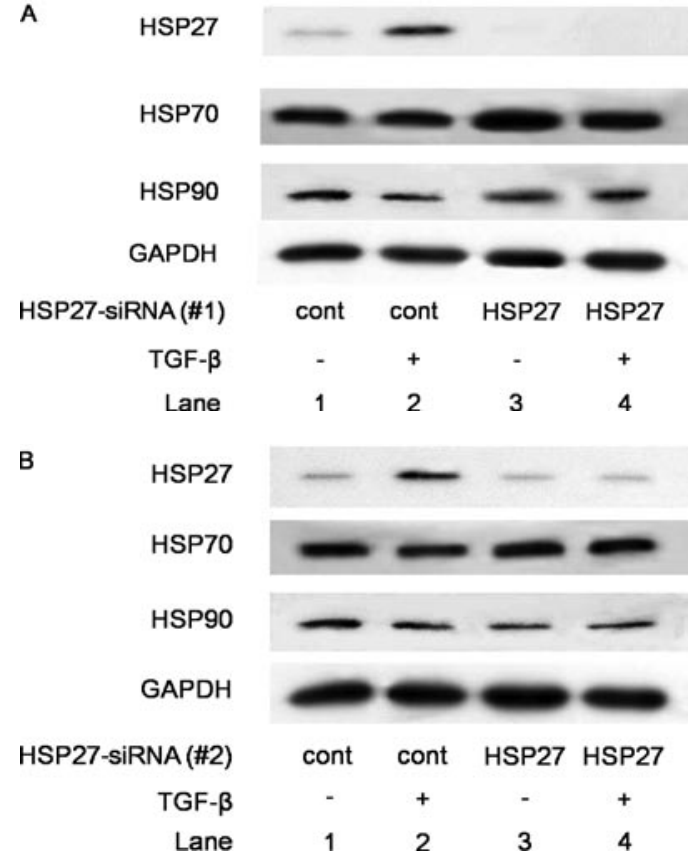

Figure 1. Effect of HSP27-siRNA on the TGF- $\beta$-stimulated HSPs induction in MC3T3-E1 cells. Cultured cells were transfected with $50 \mathrm{nM}$ control siRNA (cont) or 50 nM HSP27-siRNA using the siLentFect. (A) siRNA \#1, ID 159311, (B) siRNA \#2, ID 102070 (Ambion; HSP27). Forty-eight hours after transfection, the cells were stimulated by $5 \mathrm{ng} / \mathrm{ml}$ TGF- $\beta$ or vehicle for another $12 \mathrm{~h}$. The extracts of cells were subjected to SDS-PAGE with subsequent Western blot analysis with antibodies against HSP27, HSP70, HSP90 or GAPDH

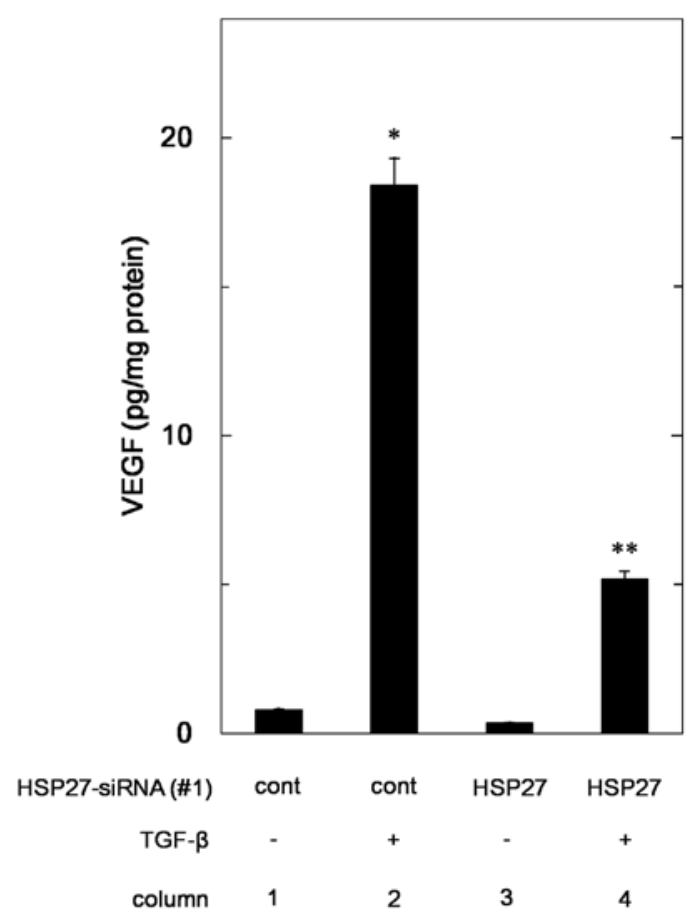

Figure 2. Effect of HSP27-siRNA on the TGF- $\beta$-stimulated VEGF release in MC3T3-E1 cells. Cultured cells were transfected with $50 \mathrm{nM}$ control siRNA (cont) or 50 nM HSP27-siRNA (siRNA \#1, ID 159311, Ambion; HSP27) using the siLentFect. Forty-eight hours after transfection, the cells were stimulated by $5 \mathrm{ng} / \mathrm{ml}$ TGF- $\beta$ or vehicle for another $48 \mathrm{~h}$. VEGF concentrations of the culture medium were determined by ELISA. Each value represents the mean \pm SEM of independent triplicate determinations. Similar results were obtained with two additional and different cell preparations. ${ }^{*} \mathrm{P}<0.05$, compared with the value of vehicle with control siRNA transfection (column 1). ${ }^{* *} \mathrm{P}<0.05$, compared with the value of TGF- $\beta$ with control siRNA transfection (column 2). 
A

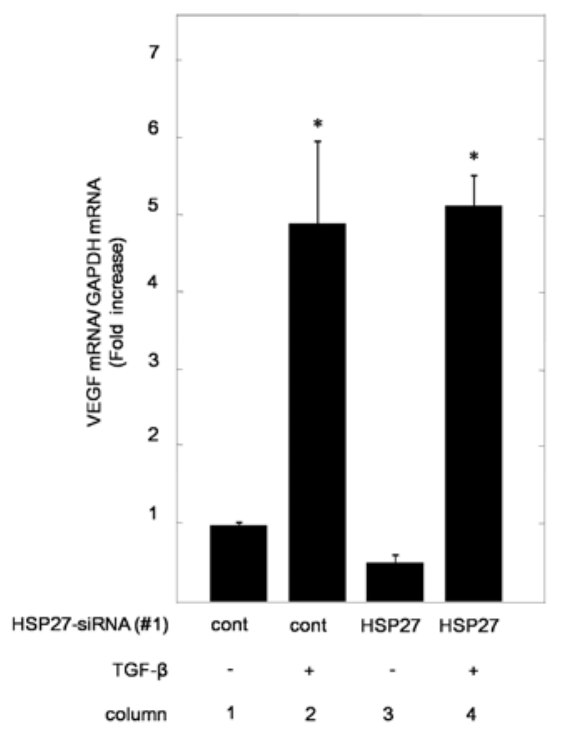

B

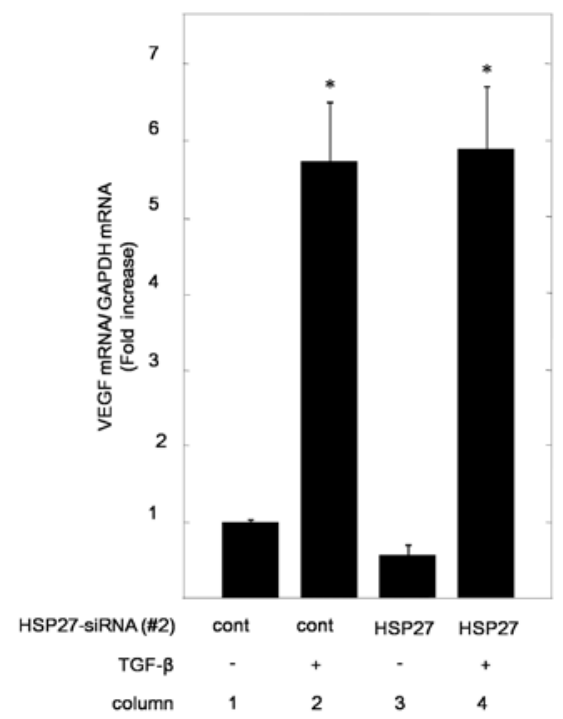

Figure 3. Effect of HSP27-siRNA on the TGF- $\beta$-stimulated VEGF mRNA expression in MC3T3-E1 cells. Cultured cells were transfected with $50 \mathrm{nM}$ control siRNA (cont) or 50 nM HSP27-siRNA. (A) siRNA \#1, ID 159311, (B) siRNA \#2, ID 102070 (Ambion; HSP27) using the siLentFect. Forty-eight hours after transfection, the cells were stimulated by $5 \mathrm{ng} / \mathrm{ml}$ TGF- $\beta$ or vehicle for another $12 \mathrm{~h}$. Total RNA was isolated and transcribed into complementary DNA. The expression of VEGF mRNA and GAPDH mRNA were quantified by real-time RT-PCR. VEGF mRNA levels were normalized to those of GAPDH mRNA. Results were standardized for the value of vehicle with control siRNA transfection. Each value represents the mean \pm SEM of independent triplicate determinations. Similar results were obtained with two additional and different cell preparations. ${ }^{\text {}} \mathrm{P}<0.05$, compared with the value of vehicle with control siRNA transfection (column 1).

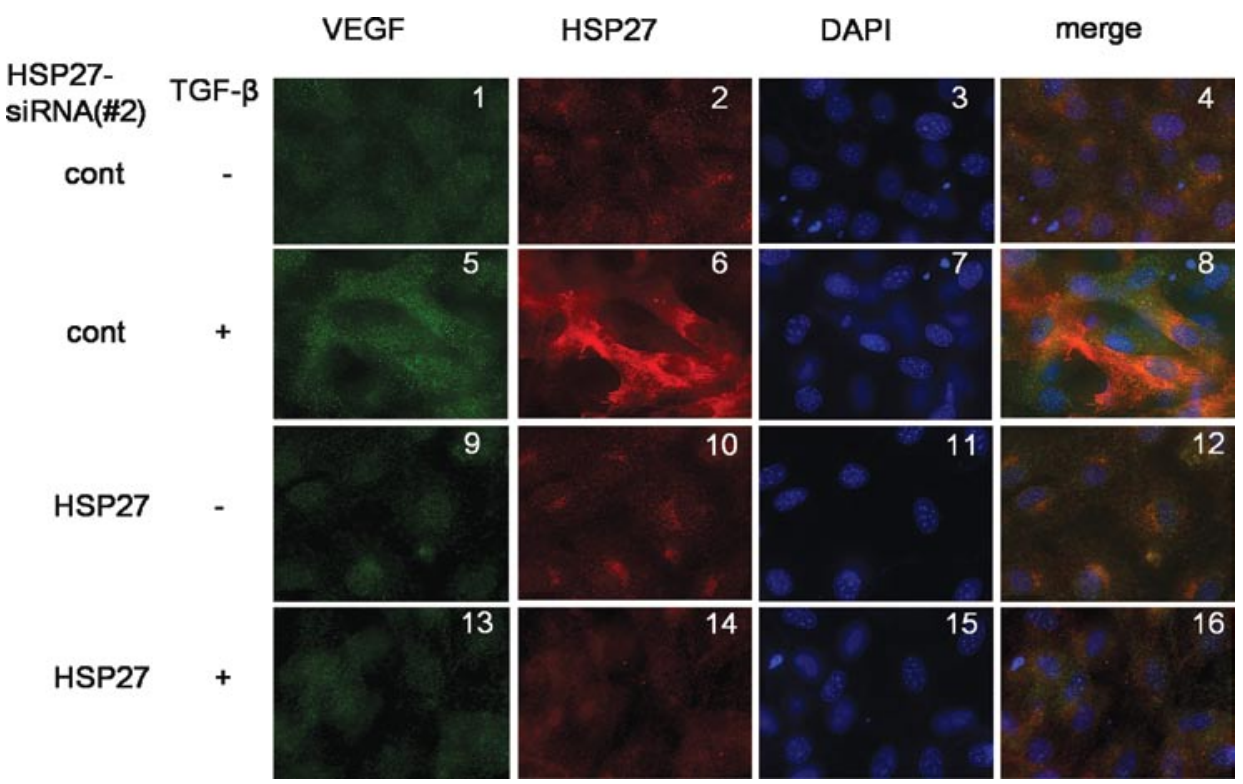

Figure 4. Immunofluorescence microscopy of HSP27 and VEGF proteins in MC3T3-E1 cells. The cells were first treated with or without siRNA of HSP27 (siRNA \#2, ID 102070, Ambion; HSP27) for $48 \mathrm{~h}$ at $37^{\circ} \mathrm{C}$, followed by stimulation with TGF- $\beta$ for $24 \mathrm{~h}$. Fixed cells were exposed to anti-VEGF and antiHSP27 antibodies (1:100 dilution) for $1 \mathrm{~h}$, followed by exposure to Alexa Fluor $488^{\circledast}$ conjugated goat anti-rabbit IgG (green signal for VEGF) and Alexa Fluor $546^{\circledast}$ conjugated goat anti-mouse IgG antibodies (red signal for HSP27). After washing, the cells were exposed to DAPI (blue signal for the nuclear) for $20 \mathrm{~min}$ and then examined by fluorescence microscopy. Representative results from at least three independent experiments are shown.

stimulated VEGF release in osteoblast-like MC3T3-E1 cells is exerted at a point upstream of the transcriptional level, we next examined the effect of HSP27 down-regulation on the TGF- $\beta$-stimulated VEGF mRNA expression. Treatment with either \#1 or \#2 HSP27-siRNA did not affect the TGF- $\beta$-induced VEGF mRNA expression detected at $12 \mathrm{~h}$ after the stimulation (Fig. 3). Similar results were obtained at $24 \mathrm{~h}$ (data not shown).
Effect of HSP27-knock down on TGF- $\beta$-stimulated VEGF induction in MC3T3-E1 cells. We further examined the effect of HSP27 down-regulation by HSP27-siRNA on VEGF induction stimulated by TGF- $\beta$ using immunofluorescence microscopy. As shown in Fig. 4, we confirmed that TGF- $\beta$ elicited both VEGF (green signal) and HSP27 (red signal) induction in the cytosol of MC3T3-E1 cells (Fig. 4, panel 5 
in comparison with panel 1 and panel 6 in comparison with panel 2, respectively). VEGF and HSP27 induction closely correlated with each other (Fig. 4, panel 8 in comparison with panel 4). HSP27-siRNA (\# 2) which alone had little effect on VEGF induction (Fig. 4, panel 9 in comparison with panel 1), clearly suppressed the TGF- $\beta$-stimulated VEGF induction in these cells (Fig. 4, panel 13 and panel 16 in comparison with panel 5 and panel 8, respectively). We found that HSP27siRNA markedly reduced the induction of HSP27 stimulated by TGF- $\beta$ (Fig. 4, panel 14 in comparison with panel 6).

\section{Discussion}

In the present study, we have shown that HSP27-knock down by siRNA suppressed the VEGF release stimulated by TGF- $\beta$ in osteoblast-like MC3T3-E1 cells. Therefore, it is likely that HSP27 induction by TGF- $\beta$ is involved in the TGF- $\beta$-induced VEGF synthesis or release in these cells. In previous studies $(17,18,24,25)$, we have shown that TGF- $\beta$ stimulates both VEGF release and HSP27 induction commonly via three major MAP kinases in osteoblast-like MC3T3-E1 cells. In addition, the maximum effect of HSP27 induction was observed at $12 \mathrm{~h}$ after the TGF- $\beta$ stimulation whereas the VEGF release reached its peak at $48 \mathrm{~h}$ after stimulation of these cells $(17,24)$. Thus the time course of HSP27 induction by TGF- $\beta$ seems to reach its peak earlier than that of VEGF release. Moreover, using immunofluorescence microscopy, we have shown that HSP27-knock down by siRNA concomitantly reduced TGF- $\beta$ stimulated induction of both HSP27 and VEGF in the cytosol of MC3T3-E1 cells. These results strongly suggest that HSP27 induction by TGF- $\beta$ plays a crucial role in the synthesis or release of VEGF stimulated by TGF- $\beta$ in osteoblasts.

On the other hand, we have demonstrated that HSP27siRNA has little effect on the VEGF mRNA expression induced by TGF- $\beta$ in MC3T3-E1 cells. Therefore, it seems unlikely that the suppressive effect of HSP27-siRNA on TGF- $\beta$-induced VEGF release is exerted at the transcriptional level. Taking our findings into account as a whole, it is most likely that HSP27 induction plays a pivotal role in TGF- $\beta$ induced VEGF release in osteoblasts, and that the effect of HSP27 is exerted at a post-transcriptional step. To the best of our knowledge, this is the first report indicating that HSP27 is involved in the intracellular signaling of TGF- $\beta$.

In bone metabolism, osteoblast-secreted VEGF plays an important role in bone remodeling through the reconstruction of local microvasculature. VEGF is an important modulator that regulates vascularization and endochondral ossification during fracture healing $(32,33)$. On the other hand, it is well recognized that TGF- $\beta$ synthesized by osteoblasts is stored in bone matrix as an inactive latent form, and takes part in the process of bone remodeling or fracture healing in its active form (16). In addition, it has been reported that TGF- $\beta$ and VEGF are actively involved in the recruitment and differentiation of mesenchymal stem cells in bone repair (34). It is probable that TGF- $\beta$-induced VEGF release from osteoblasts is implicated in the process of bone remodeling, fracture healing or metabolic bone diseases. Thus, clarifying the mechanism of TGF- $\beta$-stimulated VEGF release could provide a new therapeutic strategy for bone diseases or fracture treatment. Our present results, suggesting that the induction of
HSP27 is involved in the VEGF release stimulated by TGF- $\beta$, might create a novel therapeutic aspect in inflammatory or metabolic osteopathy and/or fracture. However, the physiological and pathological significance of HSP27 induction in osteoblasts still remains unclear. Further investigations of the detailed role of HSP27 in the TGF- $\beta$-stimulated VEGF release from osteoblasts are necessary to better understand bone metabolism and repair. In conclusion, our present results strongly suggest that HSP27 plays a pivotal role in TGF- $\beta$ stimulated VEGF release at a post-transcriptional level in osteoblasts.

\section{Acknowledgements}

We are very grateful to Yoko Kawamura for her skillful technical assistance. This investigation was supported in part by Grants-in-Aid for Scientific Research (16590873 and 16591482) from the Ministry of Education, Science, Sports and Culture of Japan, and by Research Grants for Longevity Sciences (21A-4, 21A-22) from the Ministry of Health, Labour and Welfare of Japan.

\section{References}

1. Hendrick JP and Hartl FU: Molecular chaperone functions of heat-shock proteins. Annu Rev Biochem 62: 349-384, 1993.

2. Inaguma Y, Goto S, Shinohara H, Hasegawa K, Ohshima K and Kato K: Physiological and pathological changes in levels of the two small stress proteins, HSP27 and alpha B crystallin, in rat hindlimb muscles. J Biochem 114: 378-384, 1993.

3. Benjamin IJ and McMillan DR: Stress (heat shock) proteins: molecular chaperones in cardiovascular biology and disease. Circ Res 83: 117-132, 1998.

4. Gaestel M, Schroder W, Benndorf R, Lippmann C, Buchner K, Hucho F, Erdmann VA and Bielka H: Identification of the phosphorylation sites of the murine small heat shock protein hsp25. J Biol Chem 266: 14721-14724, 1991.

5. Landry J, Lambert H, Zhou M, Lavoie JN, Hickey E, Weber LA and Anderson CW: Human HSP27 is phosphorylated at serines 78 and 82 by heat shock and mitogen-activated kinases that recognize the same amino acid motif as S6 kinase II. J Biol Chem 267: 794-803, 1992.

6. Salinthone S, Tyagi M and Gerthoffer WT: Small heat shock proteins in smooth muscle. Pharmacol Ther 119: 44-54, 2008.

7. Kostenko S, Johannessen M and Moens U: PKA-induced F-actin rearrangement requires phosphorylation of $\mathrm{Hsp} 27$ by the MAPKAP kinase MK5. Cell Signal 21: 712-718, 2009.

8. Nijweide PJ, Burger EH and Feyen JH: Cells of bone: proliferation, differentiation, and hormonal regulation. Physiol Rev 66: 855-886, 1986.

9. Kawamura H, Otsuka T, Matsuno H, Niwa M, Matsui N, Kato K, Uematsu T and Kozawa O: Endothelin-1 stimulates heat shock protein 27 induction in osteoblasts: involvement of p38 MAP kinase. Am J Physiol 277: E1046-E1054, 1999.

10. Tokuda H, Niwa M, Ishisaki A, Nakajima K, Ito H, Kato K and Kozawa O: Involvement of stress-activated protein kinase (SAPK)/c-Jun N-terminal kinase (JNK) in prostaglandin F2 $\alpha$-induced heat shock protein 27 in osteoblasts. Prostaglandins Leukot Essent Fatty Acids 70: 441-447, 2004.

11. Kozawa O, Otsuka T, Hatakeyama D, Niwa M, Matsuno H, Ito H, Kato K, Matsui N and Uematsu T: Mechanism of prostaglandin D2-stimulated heat shock protein 27 induction in osteoblasts. Cell Signal 13: 535-541, 2001.

12. Kozawa O, Niwa M, Matsuno H, Ishisaki A, Kato $\mathrm{K}$ and Uematsu T: Stimulatory effect of basic fibroblast growth factor on induction of heat shock protein 27 in osteoblasts: role of protein kinase C. Arch Biochem Biophys 388: 237-242, 2001.

13. Shakoori AR, Oberdorf AM, Owen TA, Weber LA, Hickey E, Stein JL, Lian JB and Stein GS: Expression of heat shock genes during differentiation of mammalian osteoblasts and promyelocytic leukemia cells. J Cell Biochem 48: 277-287, 1992. 
14. Massague J, Blain SW and Lo RS: TGF- $\beta$ signaling in growth control, cancer, and heritable disorders. Cell 103: 295-309, 2000.

15. Miyazono K, ten Dijke P and Heldin $\mathrm{CH}$ : TGF- $\beta$ signaling by Smad proteins. Adv Immunol 75: 115-157, 2000.

16. Bonewald LF and Mundy GR: Role of transforming growth factor- $\beta$ in bone remodeling. Clin Orthop Relat Res: 261-276, 1990.

17. Hatakeyama D, Kozawa O, Niwa M, Matsuno H, Ito H, Kato K, Tatematsu N, Shibata T and Uematsu T: Upregulation by retinoic acid of transforming growth factor- $\beta$-stimulated heat shock protein 27 induction in osteoblasts: involvement of mitogen-activated protein kinases. Biochim Biophys Acta 1589: 15-30, 2002.

18. Hayashi K, Takai S, Matsushima-Nishiwaki R, Hanai Y, Kato K, Tokuda $\mathrm{H}$ and Kozawa O: (-)-Epigallocatechin gallate reduces transforming growth factor $\beta$-stimulated HSP27 induction through the suppression of stress-activated protein kinase/c-Jun N-terminal kinase in osteoblasts. Life Sci 82: 1012-1017, 2008.

19. Ferrara N: Vascular endothelial growth factor: basic science and clinical progress. Endocr Rev 25: 581-611, 2004

20. Gerber HP, Vu TH, Ryan AM, Kowalski J, Werb Z and Ferrara N: VEGF couples hypertrophic cartilage remodeling, ossification and angiogenesis during endochondral bone formation. Nat Med 5: 623-628, 1999.

21. Goad DL, Rubin J, Wang H, Tashjian AH Jr and Patterson C: Enhanced expression of vascular endothelial growth factor in human SaOS-2 osteoblast-like cells and murine osteoblasts induced by insulin-like growth factor I. Endocrinology 137: 2262-2268, 1996.

22. Wang DS, Yamazaki K, Nohtomi K, Shizume K, Ohsumi K, Shibuya M, Demura H and Sato K: Increase of vascular endothelial growth factor mRNA expression by 1,25-dihydroxyvitamin D3 in human osteoblast-like cells. J Bone Miner Res 11: 472-479, 1996.

23. Schlaeppi JM, Gutzwiller S, Finkenzeller G and Fournier B: 1,25-Dihydroxyvitamin D3 induces the expression of vascular endothelial growth factor in osteoblastic cells. Endocr Res 23: 213-229, 1997.

24. Tokuda H, Hatakeyama D, Akamatsu S, Tanabe K, Yoshida M, Shibata T and Kozawa O: Involvement of MAP kinases in TGF- $\beta$-stimulated vascular endothelial growth factor synthesis in osteoblasts. Arch Biochem Biophys 415: 117-125, 2003.
25. Kanno Y, Ishisaki A, Yoshida M, Tokuda H, Numata $\mathrm{O}$ and Kozawa O: SAPK/JNK plays a role in transforming growth factor- $\beta$-induced VEGF synthesis in osteoblasts. Horm Metab Res 37: 140-145, 2005.

26. Sudo H, Kodama HA, Amagai Y, Yamamoto S and Kasai S In vitro differentiation and calcification in a new clonal osteogenic cell line derived from newborn mouse calvaria. J Cell Biol 96: 191-198, 1983.

27. Kozawa O, Suzuki A, Tokuda $\mathrm{H}$ and Uematsu T: Prostaglandin F2 $\alpha$ stimulates interleukin- 6 synthesis via activation of PKC in osteoblast-like cells. Am J Physiol 272: E208-E211, 1997.

28. Laemmli UK: Cleavage of structural proteins during the assembly of the head of bacteriophage T4. Nature 227: 680-685, 1970

29. Kato K, Ito H, Hasegawa K, Inaguma Y, Kozawa $\mathrm{O}$ and Asano $\mathrm{T}$ : Modulation of the stress-induced synthesis of hsp27 and $\alpha \mathrm{B}$-crystallin by cyclic AMP in C6 rat glioma cells. J Neurochem 66: 946-950, 1996.

30. Simpson DA, Feeney S, Boyle C and Stitt AW: Retinal VEGF mRNA measured by SYBR green I fluorescence: a versatile approach to quantitative PCR. Mol Vis 6: 178-183, 2000.

31. Adachi S, Shimizu M, Shirakami Y, Yamauchi J, Natsume H, Matsushima-Nishiwaki R, To S, Weinstein IB, Moriwaki $\mathrm{H}$ and Kozawa O: (-)-Epigallocatechin gallate downregulates EGF receptor via phosphorylation at Ser1046/1047 by p38 MAPK in colon cancer cells. Carcinogenesis 30: 1544-1552, 2009.

32. Ferguson C, Alpern E, Miclau T and Helms JA: Does adult fracture repair recapitulate embryonic skeletal formation? Mech Dev 87: 57-66, 1999.

33. Villars F, Bordenave L, Bareille R and Amedee J: Effect of human endothelial cells on human bone marrow stromal cell phenotype: role of VEGF? J Cell Biochem 79: 672-685, 2000.

34. Chen YJ, Wurtz T, Wang CJ, Kuo YR, Yang KD, Huang HC and Wang FS: Recruitment of mesenchymal stem cells and expression of TGF- $\beta 1$ and VEGF in the early stage of shock wave-promoted bone regeneration of segmental defect in rats. J Orthop Res 22: 526-534, 2004 